5. Fuchs, D., Chiodi, F., Ålbert, J., Åsjō, B., Hagberg, L., Hausen, A., Norkrans, G., Reibnegger, G., Werner, E. R., Wachter, H.: Neopterin concentrations in cerebrospinal fluid and serum of individuals infected with HIV-1. AIDS 3 (1989) 285-288.

6. Sönnerborg, A. B., von Stedingk, L.-V., Hansson, L.-O., Strannegård, ö.O.: Elevated neopterin and beta 2-microglobulin levels in blood and cerebrospinal fluid occur early in HIV-infection. AIDS $3\left(1989^{\circ}\right)$ 277-283.

7. Brew, B. J., Bhalla, R. B., Paul, M., Sidtis, J. J., Keilp, J. J., Sadler, A. E., Gallardo, H., McArthur, J. C., Schwartz, M. K., Price, R. W.: Cerebrospinal fluid $\beta_{2}$-microglobulin in patients with AIDS dementia complex: an expanded series including response to zidovudine treatment. AIDS 6 (1992) $461-465$.

8. Bjerrum, O. W., Birgens, H. S.: Measurement of $\beta_{2}$-microglobulin in serum and plasma by an enzyme-linked immunosorbent assay (ELISA). Clin. Chim. Acta 155 (1986) 69-76.

9. Wikkelso, C., Andersson, M., Andersson, R., Blomstrand, C.: Isoelectric focusing followed by silver staining. A suitable method for routine investigation of cerebrospinal fluid protein. Eur. Neurol. 23 (1984) 306-312.
10. Jacobson, M. A., Abrams, D. I., Volberding, P. A., Bacchetti, P., Wilber, J., Chaisson, R. E., Crowe, S., Howard, W., Moss, A.: Serum beta 2 -microglobulin decreases in patients with AIDS or ARC treated with azidothymidine. J. Infect. Dis. 159 (1989) 1029-1036.

11. Yarchoan, R., Klecker, R. W., Weinhold, K. J., Markham, P. D., Lyerly, H. K., Durack, D. T., Gelman, E., Lehrman, S. N., Blum, R. M., Barry, D. W., Shearer, G. M., Fischl, A. A., Mitsuya, H., Gallo, R. C., Collins, J. M., Bolognesi, D. P., Myers, C. E., Broder, S.: Administration of 3'-azido-3'deoxythymidine, an inhibitor of HTLV-III/LAV replication, to patients with AIDS or AIDS-related complex. Lancet i (1986) 575-580.

12. Portegies, P., de Gans, J., Lange, J. M. A., Derix, M. M. A., Speelman, H., Bakker, M., Danner, S. A., Goudsmit, J.: Declining incidence of AIDS dementia complex after introduction of zidovudine treatment. Br. Med. J. 2 (1989) 819-821.

13. Brew, B. J., Bhalla, R. B., Paul, M., Gallardo, H., McArthur, J. C., Schwartz, M. K., Price, R. W.: Cerebrospinal fluid neopterin in human immunodeficiency virus type 1 infection. Ann. Neurol. 28 (1990) 556-560.

\title{
Wellcome Stipendium für klinische Virologie erstmals vergeben
}

Mit DM 100.000,- dotiertes Stipendium für klinische Virologie ins Leben gerufen.

Im Rahmen des DVV-Workshops (Deutsche Vereinigung zur Bekämpfung von Viruskrankheiten) in Erfurt gab Professor Günther Maass, Münster, die Namen der Stipendiaten bekannt: Frau Dr. med. Britta Köppe, Aachen, Dipl. med. Lutz Franke von der Charité in Berlin und den Biologen Christoph Geiger vom MaxPlanck-Institut für Biochemie in München.

Anläßlich der nächsten DVV-Tagung werden die Stipendiaten über erste Ergebnisse berichten.
Der DVV-Workshop in Hamburg am 8. und 9. Oktober 1994 wird auch wieder den Rahmen für die Stipendiumsvergabe bilden. Bewerber richten ihre Anfrage an: Büro Wellcome Forschungsstipendium, Bodelschwinghstraße 17, 2000 Hamburg 63. Der letzte Termin für Anträge ist der 31. Mai 1994. Dem Fachbeirat gehören an: Professor Eichenlaub, Professor Maass, Frau Professor RübsamenWaigmann, Professor Wagner und Professor Wutzler. 